\title{
Dynamic assessment of construction materials in urban building stocks - A critical review
}

\author{
Authors: Verena Göswein ${ }^{1 *}$, José Dinis Silvestre ${ }^{1}$, Guillaume Habert ${ }^{2}$, Fausto Freire ${ }^{3}$ \\ ${ }^{1}$ CERIS, Department of Civil Engineering, Architecture and Georesources, Instituto Superior Técnico, \\ Universidade de Lisboa, Av. Rovisco Pais 1, 1049-001, Lisbon, Portugal \\ ${ }^{2}$ Chair of Sustainable Construction, IBI, ETH Zürich, Stefano-Franscini-Platz 5, 8093 Zurich, Switzerland \\ ${ }^{3}$ ADAI-LAETA, Department of Mechanical Engineering, University of Coimbra, Polo II Campus, R. Luís \\ Reis Santos, 3030-788 Coimbra, Portugal \\ *Corresponding author: verena.goswein@tecnico.ulisboa.pt
}

\section{Contents}

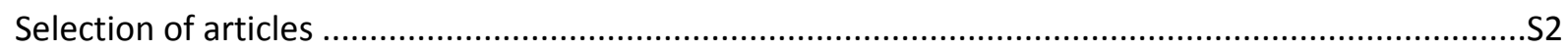

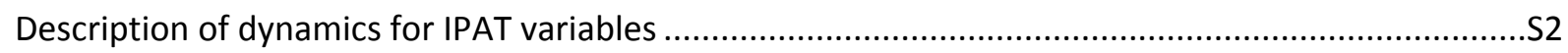

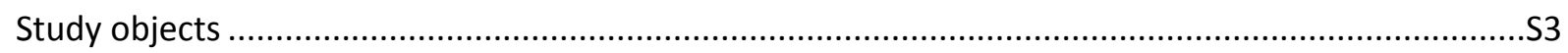

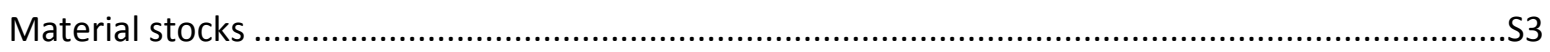

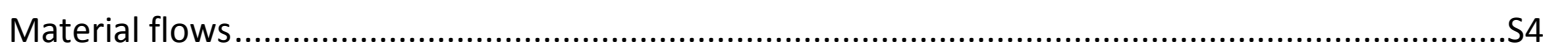

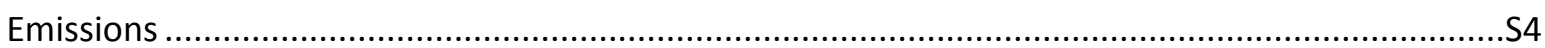

Number of pages: 5

Number of figures: 0

Number of tables: 1

Note: For full references please refer to the main article. 


\section{Selection of articles}

The review was conducted on papers retrieved from the Scopus database. Only articles from international peer-reviewed journals were taken into account. Furthermore, to thwart the Matthew effect ${ }^{1}$, the search was separately conducted on "ScienceDirect", the "Wiley Online Library", and "TandFonline".

The search terms used were "life cycle OR LCA OR environmental assessment", "material flow OR material stock or MFA", "maps OR mapping OR GIS OR geoinformation OR spatial analysis" AND "building stock OR housing stock OR dwellings OR city OR neighborhood OR urban" AND "dynamic OR over time OR years OR spatial distribution OR in space". The initial search yielded more than 200 papers, many of them older than ten years and centering around the pure quantification of material stocks and generic UM studies without any dynamic model inputs. Therefore, we decided to only include articles that were published during the last ten years, i.e. in or after the year 2008. Further strategic filtering steps to extract papers that deal with the sustainable built environment were applied. In addition, individual reading efforts helped excluding papers. These papers, even though dealing with questions of dynamics of urban building stocks, used definitions of dynamic or urban building stock that in fact did not match the envisioned target of the present study as described above, or which had the focus not on materials but exclusively on energy. For a paper to be included in the review, its analysis must have considered some kind of spatial or temporal dynamic.

\section{Description of dynamics for IPAT variables}

Table S1 lists, per type of dynamic, a definition and units for each variable of the adapted IPAT equation as used in the review.

Table S1: Parameters and units for each parameter of the adapted IPAT equation and for the three types of dynamics under study.

\begin{tabular}{|l|l|l|l|l|l|}
\hline \multirow{2}{*}{} & \multicolumn{1}{|c|}{ Output } & \multicolumn{3}{|c|}{ Input } \\
\cline { 2 - 6 } & Impact & Population & Affluence & Material Intensity & Emission Intensity \\
\hline $\begin{array}{l}\text { Parameters } \\
\text { and unit }\end{array}$ & $\begin{array}{l}\text { Materials or } \\
\text { emissions } \\
\text { e.g. }[\mathrm{kg} \text { of } \\
\text { concrete] or } \\
{\left[\begin{array}{l}\text { kg of } \mathrm{CO}_{2} \\
\text { eqv.] }\end{array}\right.}\end{array}$ & $\begin{array}{l}\text { Buildings, } \\
\text { apartments } \\
\text { or people } \\
\text { e.g. [number } \\
\text { of buildings] }]\end{array}$ & $\begin{array}{l}\text { Floor area, or volume, } \\
\text { per person, or per } \\
\text { apartment, or per } \\
\text { building } \\
\text { e.g. }\left[\mathrm{m}^{2} / \mathrm{person}\right] \text { or } \\
{\left[\mathrm{m}^{3} / \mathrm{building]}\right.}\end{array}$ & $\begin{array}{l}\text { Material per floor } \\
\text { area or building } \\
\text { volume } \\
\text { e.g. }[\mathrm{kg} \text { of } \\
\left.\text { concrete } / \mathrm{m}^{2}\right]\end{array}$ & $\begin{array}{l}\text { Emission per } \\
\text { material } \\
\text { e.g. }\left[\mathrm{kg} \text { of } \mathrm{CO}_{2}\right. \\
\text { eqv./kg of concrete] }\end{array}$ \\
\hline $\begin{array}{l}\text { Spatial } \\
\text { dynamic }\end{array}$ & $\begin{array}{l}\text { Amount per } \\
\text { location or } \\
\text { area, on a } \\
\text { scale that is } \\
\text { smaller } \\
\text { than case } \\
\text { study } \\
\text { boundaries }\end{array}$ & $\begin{array}{l}\text { Amount per } \\
\text { location or } \\
\text { area, on a } \\
\text { scale that is } \\
\text { smaller than } \\
\text { case study } \\
\text { boundaries }\end{array}$ & $\begin{array}{l}\text { Differences between } \\
\text { locations or areas, on } \\
\text { a scale that is smaller } \\
\text { than case study } \\
\text { boundaries }\end{array}$ & $\begin{array}{l}\text { Differences } \\
\text { between locations } \\
\text { or areas, on a scale } \\
\text { that is smaller than } \\
\text { case study } \\
\text { boundaries }\end{array}$ & $\begin{array}{l}\text { locations or areas, } \\
\text { on a scale that is } \\
\text { smaller than case } \\
\text { study boundaries }\end{array}$ \\
\hline
\end{tabular}

\footnotetext{
${ }^{1}$ Beel, J.; Gipp, B. Proceedings of ISSI 2013 Vienna: 14th International Society of Scientometrics and Informetrics Conference, Vienna, Austria, 15th to 20th July, 2013. In Proceedings of ISSI 2013 Vienna: 14th International Society of Scientometrics and Informetrics Conference, Vienna, Austria, 15th to 20th July, 2013; Austrian Institut of Technology : ISSI: Vienna, 2013.
} 


\begin{tabular}{|c|c|c|c|c|c|}
\hline $\begin{array}{l}\text { Evolutionary } \\
\text { temporal } \\
\text { dynamic }\end{array}$ & $\begin{array}{l}\text { Amount (for } \\
\text { same } \\
\text { location or } \\
\text { area that } \\
\text { can be } \\
\text { equal to or } \\
\text { smaller } \\
\text { than spatial } \\
\text { boundaries } \\
\text { of case } \\
\text { study) for } \\
\text { different } \\
\text { time steps }\end{array}$ & $\begin{array}{l}\text { Amount (for } \\
\text { same } \\
\text { location or } \\
\text { area that } \\
\text { can be } \\
\text { equal to or } \\
\text { smaller than } \\
\text { spatial } \\
\text { boundaries } \\
\text { of case } \\
\text { study) for } \\
\text { different } \\
\text { time steps }\end{array}$ & $\begin{array}{l}\text { Total or relative } \\
\text { evolution (for same } \\
\text { location or area that } \\
\text { can be equal to or } \\
\text { smaller than spatial } \\
\text { boundaries of case } \\
\text { study) for different } \\
\text { time steps }\end{array}$ & $\begin{array}{l}\text { Total or relative } \\
\text { evolution (for same } \\
\text { location or area that } \\
\text { can be equal to or } \\
\text { smaller than spatial } \\
\text { boundaries of case } \\
\text { study) for different } \\
\text { time steps }\end{array}$ & $\begin{array}{l}\text { Total or relative } \\
\text { evolution (for same } \\
\text { location or area that } \\
\text { can be equal to or } \\
\text { smaller than spatial } \\
\text { boundaries of case } \\
\text { study) for different } \\
\text { time steps }\end{array}$ \\
\hline $\begin{array}{l}\text { Inter- } \\
\text { building- } \\
\text { clusters } \\
\text { dynamic }\end{array}$ & -- & -- & $\begin{array}{l}\text { Differences between } \\
\text { items ((groups of) } \\
\text { person(s)/building(s) } \\
\text { that are characterized } \\
\text { by same attribute, e.g. } \\
\text { construction year), for } \\
\text { one moment in time } \\
\text { (for same location or } \\
\text { area that can be equal } \\
\text { to or smaller than } \\
\text { spatial boundaries of } \\
\text { case study) }\end{array}$ & $\begin{array}{l}\text { Differences } \\
\text { between items } \\
\text { ((groups of) } \\
\text { building(s)) that are } \\
\text { characterized by } \\
\text { same attribute, e.g. } \\
\text { construction year), } \\
\text { for one moment in } \\
\text { time (for same } \\
\text { location or area that } \\
\text { can be equal to or } \\
\text { smaller than spatial } \\
\text { boundaries of case } \\
\text { study) }\end{array}$ & -- \\
\hline
\end{tabular}

\section{Study objects}

\section{Material stocks}

Ten papers were identified that provide an analysis of material stocks, including or focusing on the quantification of construction materials.

The following four studies focus purely on the accumulation aspect employing MFA. However, while Barles (2009), Browne et al. (2011) and Rosado et al. (2014) are more general UM studies quantifying different types of resource use, Condeixa et al. (2017) quantifies the materials-in-use on the residential building stock. Barles (2009) and Browne et al. (2011) applied the Eurostat method (Eurostat 2001), which was developed by the statistical office of the European communities. The method was originally tailored for studies at the national scale and had to be adapted to make it usable at a local scale. For this purpose, it was assumed that the data needed, originally at the national scale, is also available at a smaller scale. Rosado et al. (2014) described their own top-down methodology called "Urban Metabolism Analyst Model" to fill in gaps of previous UM studies, the most important one being the availability of urban scale data. They also criticized that often Eurostat-based studies categorize materials into five classes making results rigid and inadequate to understand the composition of larger material stocks regarding their recycling potential. Condeixa et al. (2017) is more specific in her quantification of building material stock, referring to the material needed for the maintenance of a current residential building stock, and its mortality rate of buildings depending on type of building and its structure.

The other six studies that were identified belonging to the objective "Material stocks" combine the tool MFA with GIS for a more complex analysis. Kleemann et al. (2016) and Tanikawa and Hashimoto (2009) perform GIS-based analyses to allow for a geo-localized identification of material stocks to obtain a resource cadaster and inform C\&D waste strategies. 
The question of material quantification from demolished buildings goes one step further than the pure study of material stocks by linking the material quantities with other indicators. Among these indicators are economic value and recycling method (Wu et al. 2016), the identification of hot spots of valuable material (Cheng et al. 2018), and focus on the life cycle phase End of Life (EoL) through a better understanding of actual demolition activity (Kleemann et al. 2017). García-Torres et al. (2017) analyzed debris after a potential seismic event in an earthquake prone zone. This application shows that even within the narrow field of understanding materials arising from demolition, or in this case, the end of life of buildings through an earthquake, there is still a wide range of possible applications and challenges to be investigated.

\section{Material flows}

Five studies were identified with the objective of informing on material flows. All of those employed MFA as a tool, with three of them combining MFA with GIS and one that combines MFA with GIS and LCA.

Hu et al. (2010) used only MFA to study future construction and demolition waste, based on the stock dynamics driven material flow model developed by Müller (2006). This model has been applied to various contexts. It uses per capita floor area as a proxy for affluence, along with population growth, as stock drivers.

Roy et al. (2015) advocated for a platform that serves the industrial ecology - spatial planning nexus. With a simple building stock model that only considers three types of buildings, and scenario analysis, they analyzed factors governing material flows related to demolition, construction and renovation by combining MFA with GIS.

Stephan and Athanassiadis (2018) combined MFA with GIS as well. Again, these authors want the results of their MFA to contribute to a more circular economy and inform spatial planning. However, in a different context: they focused on material flows related to replacement activities during buildings' use phase.

Han et al. (2018) and Heeren and Hellweg (2018) performed some of the most advanced MFA, in terms of data collection, included in this review to study material flows. The first ones collected spatial data from various sources to analyze past material input and output flows related to development of residential buildings, roads, railways and the subway in Shanghai. The latter ones used a probabilistic modeling approach to account for the whole Swiss residential building stock. Even though not matching the neighborhood to district scale criteria, this study was still included in this review. Thanks to the qualitative and quantitative features of the models input data, its results are representative for groups with more than 400 buildings, which allows conclusions at the approximate neighborhood scale. The authors employed scenario analysis to simulate different potential futures in terms of renewal rate, refurbishment standard and materials used, allowing for conclusions on changing material demand.

\section{Emissions}

Thirteen studies were identified that opted to quantify emissions at the urban scale as study object, usually with LCA. The study of emissions is based on materials in stock, for emissions from the use stage, on material inflows, for embodied emissions, and on material outflows, for the emissions of waste generated at the end of life of buildings and materials. Therefore, all studies classified under the study object "emissions" also analyze the material stocks or flows of their case study. However, the focus here is not on the analysis and interpretation of material quantities but of emissions. 
Stephan et al. 2013 performed an embodied energy assessment of an existing neighborhood for the next 100 years. They relied on a hybrid technique that combines input-output tables with process analysis. The building stock model they used merely serves as a testing ground for various scenarios regarding size and typology of houses and others. Heeren et al. (2013) couples his material stock model with LCA to obtain a lifecycle-based building stock model, allowing to translate material stocks and flows to related emissions. Stephan and Athanassiadis (2017) focused on the analysis of embodied environmental impacts of Melbourne's building stock and employed a process-based hybrid analysis approach, offering a comprehensive LC inventory and extensive system boundaries. Nichols and Kockelmann (2014) analyzed different components of the residential built environment, focusing on operational and embodied energy. They compared four different neighborhoods in Texas through coupling MFA with GIS. They concluded that population density and household size can yield the biggest per capita energy savings.

The study of Shahrokni et al. (2015) is different from the other studies regarding the input data of the model, which needs to be in real time. The authors advocate for the use of big data in their concept of "smart urban metabolism" to provide a better understanding of resource use and related GHG emissions to the final user. Their model allows analyzing any type of construction intervention as long as the (new) buildings are equipped with smart meters to collect the necessary data in real time.

Similarly to Hu et al.'s (2010) material flow study, Abelwi et al.'s (2017) study of Riyadh and Göswein et al.'s (2018) study of Johannesburg uses a stock dynamics driven material flow model. Abelwi et al. (2017) analyzed future energy and $\mathrm{CO}_{2}$ emissions for a baseline and high growth scenarios for population, as well as a scenario with an alternative energy mix. Göswein et al. (2018) quantified the materials and embodied $\mathrm{CO}_{2}$ emissions of new construction. With all three case studies being rapidly growing cities in developing countries, it seems that the stock dynamics driven model, using per capita floor area as a driver, is useful in such contexts, which might be related to the difficult question of how to account for decoupling effects in models (Ward et al. 2016). Abelwi et al. (2017) and Göswein et al. (2018) used lifetime distributions, a normal and lognormal ones respectively, to model output flows at the end of life of buildings and materials. Reyna and Chester (2014) performed an advanced MFA combining it with GIS and LCA to assess growth and decay of the Los Angeles building stock. They did not employ a simple lifetime distribution but instead their analysis is based on a growth model to estimate turnover rates.

García-Pérez et al. (2018) analyzed "retrofit" interventions. They compared insulation materials with a cradle to site LCA. One of the materials studied is cork-based and the authors analyzed and showed the benefit of biogenic carbon for the Global Warming Potential (GWP). Three more studies focused on energy and GHG emissions related to retrofit: Seo et al. (2018) found that embodied emissions become more important with an increased efficiency buildings' operation. Harter et al. (2017) investigated the modernization of urban areas, concluding that for their case study in Stöckach, Stuttgart, Germany, and from an environmental point of view, refurbishment is better than new construction. Geyer et al. (2017) propose a more advanced, GIS-based, clustering methodology to tailor retrofit interventions for the building stock of a Swiss village, using exhaustive data.

Mastrucci et al. (2017) focused on the EoL phase of buildings and evaluated the potential emissions through combining MFA with LCA and GIS. They included credits for recycling and downcycling by introducing gravel as avoided product. 